\title{
Transient Drug-Induced Myopia
}

\author{
Kaimbo DKW* \\ Department of Ophthalmology and Biophysics, University of Kinshasa, Congo
}

*Corresponding author: Kaimbo DKW, MD, PhD, Department of Ophthalmology and Biophysics, University of Kinshasa, Congo, Tel: +243998238928, E-mail: dieudonne_kaimbo@yahoo.com

Citation: Kaimbo DKW (2014) Transient Drug-Induced Myopia. SAJ Case Rep 1: 105. doi: 10.18875/23757043.1.105

Article history: Received: 26 June 2014, Accepted: 12 August 2014, Published: 14 August 2014

\begin{abstract}
Myopia (nearsightedness) is a refractive error, a condition in which the cornea and lens of the nonaccommoding eye have too much plus power for the length of eye. As a result, images of distant objects are focused in front of the retina and thus appear blurred. Transient drug-induced myopia is a myopia induced by a drug as a transient side effect. Several case reports of transient drug-induced myopia have been reported. These cases have been associated with secondary angle closure glaucoma and other ocular conditions such as choroidal detachment, maculopathy, retinal folds. Drugs known to produce this effect include sulfa drugs and other medications. The possible mechanism is thought to be an allergic reaction to the drug. Both ciliary muscle contraction and ciliary body edema may play role in the pathomechanism. Differential diagnosis is made with a number of conditions, either ocular in origin or associated with an underlying systemic cause. Discontinuation of medications leads to complete resolution of the anatomic shift.
\end{abstract}

Keywords: Transient; Drug-induced myopia; Myopia; Sulfonamide; Drugs; Side effects

Myopia is the most common eye disease and is one of the leading causes of vision impairment worldwide [1,2]. Prevalence of myopia is significantly different among racial groups, although its worldwide prevalence is approximately 30\% (3\%-84\%) [3]. The highest prevalence is found in East Asia, such as mainland China [3]. The prevalence of myopia in the US population was estimated in the early 1970 s to be $25 \%$ in persons aged 12 to 54 years [4]. A recent meta-analysis of population-based studies found a prevalence of $25 \%$ in persons over age 40 [5].

Myopia (nearsightedness) is a refractive error, a condition in which the cornea and lens of the nonaccommoding eye have too much plus power for the length of eye. As a result, images of distant objects are focused in front of the retina and thus appear blurred.

Myopia has been recognized as a distinct visual disability for millennia and has been known for more than 2000 years and was first described by the ancient Greeks [6,7]. It was probably the ancient Greeks who coined the term, using the roots myein (to close) and ops (eye) to characterize those individuals who narrow their eyelids to improve distance visual acuity, the pinhole effect. The focus of distant parallel rays of light falls anterior to the retinal plane and produces a blurred image in myopia. This situation can arise because either the primary refractive components are too powerful or the globe is too long. Thus, myopia can be due to increased corneal or lenticular curvature, or an increase in the lens index of refraction, as occurs with the development of nuclear sclerosis. More commonly, myopia is the result of axial elongation of the posterior segment of the eye.

Transient drug-induced myopia is a myopia induced by a drug as a transient side effect. A side effect (adverse drug reaction) is basically an unintended, unwanted occurrence that results from taking a drug. An adverse drug reaction is an expression that describes harm associated with the use of given medication at a normal dosage during normal use. Adverse drug reactions may occur following a single dose or prolonged administration of a drug or result from the combination of two or more drugs [8]. All drugs that come in the market may cause side effects, where many are minor and few are serious.

Several case reports of transient drug-induced myopia have been reported. These cases have been associated with secondary angle closure glaucoma and other ocular conditions such as choroidal detachment, maculopathy, retinal folds [9]. Drugs known to produce this effect include sulfa drugs. Ingestion of sulphonamide-derived drugs has been reported to possibly have ocular side-effects [1015]. Among these drugs are acetazolamide (Diamox) [16-21], indapamide [22,23], sulphasalazine [24], methazolamide [25], co- 
trimoxazole [26,27], ethoxzolamide (Cardrase) [28], hydrochlorothiazide (Hydrodiuril) [29-31], chlorthalidone (Hygroton) [15], psychotropic agents [32].

Several case reports of a similar condition have been published following the use of topiramate, a sulfonamide derivative used for treatment of migraine headaches, seizures, alcohol abuse and other drug dependencies [15, 33-51].

Transient myopia can also be caused by other drugs such as promethazine hydrochloride (Phenergan) [52], prochlorperazine (Compazine) [53], insulin [54-57], IGF1 and FGF2 [58], antithrombotic [59], opiate [60], tetracycline [15,61], aripiprazole [62,63], amisulpride [64], oseltamivir [65], mefenamic acid [66], ectasy [67], phendimetrazine and ephedrine used as anorexiants [68], equine antilymphocyte globulins [69], metronidazole [70], aspirine and deturgylone [71,72], isotretinoin (accutane) [3], isosorbide dinitrate [74], quinine [75].

\section{Mechanism of transient drug-induced myopia}

Drugs may induce refractive power of the eye by one of three mechanisms: [1] substained contraction (spasm) of the ciliary muscle, causing increased refractivity of the lens; [2] increases refractive power of the lens contents as the result of water imbibition; and [3] swelling of the cilairy processes, causing forward displacement of the lens. Increased refractive power of the lens or sustained accommodation increased myopia.

The possible mechanism is thought to be an allergic reaction to the drug. Both ciliary muscle contraction and ciliary body edema play a role in the pathomechanism. Ultra Biomicroscopy (UBM) explains this mechanism by demonstrating supraciliary choroidal (ciliochoroidal) effusion causing forward displacement of the ciliary body-lens-iris block (diaphragm) and relaxation of zonular fibers leading to myopia, anterior chamber shallowing and angle closure glaucoma [76].

\section{Clinical presentation}

Patients present with headache, pain and sudden bilateral loss of distant vision with normal vision at near representing the myopic shift, and occurring prior to symptoms and elevated intraocular pressure. Patients present acute onset of blurry vision and have features of bilateral acute angle closure, myopic shift and elevated intraocular pressure. Examination shows anterior chamber flattening combined with lens thickening and echography disclosed bilateral 360 degrees shallow choroidal detachments. Clinical presentation is variable, not all patients have the complete presentation.

\section{Differential diagnosis}

Transient myopia has been reported to occur in a number of conditions, either ocular in origin or associated with an underlying systemic cause. Other causes of transient myopia may include:

1. Nearwork-induced transient myopia: after a sustained near task, near work $[77,78]$.

2. Transient myopic shift after phakic intraocular lens implantation [79]: a potential complication of iris-claw pIntraOcularLens implantation.

3. Transient myopic shift following inflammation. Myopic changes induced by inflammatory diseases can occur in uveitis. Uveitic conditions that can induce a myopic shift include sclero-choroidal inflammation, lens induced myopia due to steroid cataracts, juvenile idiopathic arthritis (JIA) induced myopia; Uveitis can cause acute, transient or constitutive myopization in different contexts. These include acute inflammation such as in choroidal or scleral inflammation, chronic uveitis as in juvenile idiopathic arthritis (JIA) related uveitis, as a consequence of therapy such as lens related myopization following long-term corticosteroid therapy [80].

4. Transient myopia following (blunt) trauma [81-85]: Transient myopia after blunt trauma is caused by anatomic changes in the ciliary body and crystalline lens. It is noted an anterior lens displacement, increased lens thickness probably due to lens edema, choroidal detachment, and ciliary body edema. Ultrasound imaging shows an iridocorneal angle closure that could have led to angle-closure glaucoma. UBM shows also an annular ciliochoroidal effusion with ciliary body edema, anterior rotation of the ciliary processes, and disappearance of the ciliary sulcus. Transient myopia following blunt trauma is a rare transient situation which may be seen in the injured eye or both eyes after blunt ocular trauma. Myopia may have been due to ciliary spasm arising from stimulation of the efferent autonomic system and ciliary body edema.

5. Transient myopic shifting in systemic lupus erythematosus [86-88]: The ocular complications could be related to antiphospholipid syndrome.

6. Transient myopia in systemic tuberculosis [89]: a rare presenting feature of systemic tuberculosis; sudden onset blurred distance vision and fever are observed; anterior segment examination reveals narrow angles on gonioscopy.

7. Transient myopic shift after pars plana vitrectomy [90,91] and after panretinal photocoagulation [92]. Choroidal effusion is noted.

8. Other considerations in a patient with narrow angles similarly caused by a ciliochoroidal effusion include scleritis, uveitis, juvenile idiopathic arthritis, tumors such as retinoblastoma and medulloepithelioma (in the child), and exudative retinal detachments. 


\section{Treatment}

Discontinuation of these medications leads to complete resolution of the anatomic shift. The ocular and myopic changes clear up completely. Ciliochoroidal effusion, transient myopia resolve and rapid resolution of angle closure occurs after discontinuation of the drug. If intraocular pressure remains uncontrolled, additional therapies such as topical intraocular pressure-lowering medications may need to be considered. Active measures like cycloplegic may play a role, too short.

\section{References}

1. Vitale S, Sperduto RD, Ferris FL (2009) Increased prevalence of myopia in the United States between 1971-1972 and 1999-2004. Arch Ophthalmol 127: 1632-9.

2. You QS, Xu L, Yang H, Wang YX, Jonas JB (2011) Five-year incidence of visual impairment and blindness in adult. Chinese: the Beijing eye study. Ophthalmology 118: 1069-75.

3. Edwards MH, Lam CS (2004) The epidemiology of myopia in Hong Kong. Ann Acad Med Singapore 33: 34-8.

4. Sperduto RD, Seigel D, Roberts J, Rowland M (1983) Prevalence of myopia in the United States. Arch Ophthalmol 101: 405-7.

5. Kempen JH1, Mitchell P, Lee KE, Tielsch JM, Broman AT, et al. (2004) The prevalence of refractive errors among adults in the United States, Western Europe, and Australia. Arch Ophthalmol 122: 495-505.

6. Donders FC (1866) Die Anomalien der Refraction und Accommodation des Auges: 279-379.

7. Hirschberg J (1985) The history of ophthalmology: The middle ages; the sixteenth and seventeenth centuries. West Germany 2: 263-79.

8. Nebeker JR, Barach P, Samore MH (2004) Clarifying adverse drug events: aclinician's guide to terminology, documentation, and reporting. Ann Intern Med 140: 795-801.

9. Natesh S, Rajashekhara SK, Rao ASD, Shetty RB, (2010) Topiramate-induced angle closure with acute myopia, macular striae. Oman J Ophthalmolo 3: 26-8.

10. Kramb RA (1952) A case of transient myopia due to ingestion of sulfa. Am J Optom Arch Am Acad Optom 29: 209-11.

11. Bovino JA, Marcus DF (1982) The mechanism of transient myopia induced by sulfonamide therapy. Am J Ophthalmol 94: 99-102.

12. Maddalena MA (1968) Transient myopia associated with acute glaucoma and retinal edema following vaginal administration of sulfanilamide. Arch Ophthalmol 80: 186-8.

13. Chirls IA, Norris JW (1984) Transient myopia associated with vaginal sulfanilamide suppositories. Am J Ophthalmol 98: 120-1.

14. Laval J (1986) Transient myopia induced by sulfonamides. Am J Ophthalmol 102: 283-4.

15. Panday VA, Rhee DJ (2007) Review of sulfonamide-induced acute myopia and acute bilateral angle-closure glaucoma. Compr Ophthalmol Update 8: 271-6. 16. Cristiansson J (1958) Transient myopia after the administration of diamox. Acta Ophthalmol (Copenh) 36: 356-7.

17. Halpern AE, Kulvin MM (1959) Transient myopia during treatment with carbonic anhydrase inhibitors. Am J Ophthalmol 48: 534-5.

18. Muirhead JF, Scheie HG (1960) Transient myopia after acetazolamide. Arch Ophthalmol 63: 315-8.

19. Fan JT, Johnson DH, Burk RR (1993) Transient myopia, angle-closure glaucoma, and choroidal detachment after oral acetazolamide. Am J Ophthalmol 115: $813-4$.

20. Krieg PH, Schipper I (1996) Drug-induced ciliary body oedema: a new theory. Eye (Lond) 10: 121-6.

21. Szawarski P, Hall-Thompson B (2009) Acetazolamide-induced myopia at altitude. Wilderness Environ Med 20: 300-1.

22. Végh M, Hári-Kovács A, Réz K, Tapasztó B, Szabó A, et al. (2013) Indapamide-induced transient myopia with supraciliary effusion: case report. BMC Ophthalmol 13: 58.

23. Blain P, Paques M, Massin P, Erginay A, Santiago P, et al. (2000) Acute transient myopia induced by indapamide. Am J Ophthalmol 129: 538-40.

24. Santodomingo-Rubido J, Gilmartin B, Wolffsohn JS (2003) Drug-induced bilateral transient myopia with the sulphonamide sulphasalazine. Ophthalmic Physiol Opt 23: 567-70.

25. Kwon SJ, Park DH, Shin JP (2012) Bilateral transient myopia, angle-closure glaucoma, and choroidal detachment induced by methazolamide. Jpn J Ophthalmol 56: 515-7.

26. Spadoni VS, Pizzol MM, Muniz CH, Melamed J, Fortes Filho JB (2007) Bilateral angle-closure glaucoma induced by trimetoprim and sulfamethoxazole combination: case report [Article in Portuguese]. Arq Bras Oftalmol 70: 517-20.

27. Kamath S, Acharya N, Nithyanandam S (2012) Co-trimoxazole-induced myopia in an HIV-positive patient. Int J STD AIDS 23: 71-2.

28. Beasley FJ (1962) Transient myopia and retinal edema during ethoxzolamide (cardrase) therapy. Arch Ophthalmol 68: 490-1.

29. Beasley FJ (1961) Transient myopia and retinal edema during hydrochlorothiazide (hydrodiuril) therapy. Arch Ophthalmol 65: 212-3.

30. Söylev MF, Green RL, Feldon SE (1995) Choroidal effusion as a mechanism for transient myopia induced by hydrochlorothiazide and triamterene. Am J Ophthalmol 120: 395-7.

31. Roh YR, Woo SJ, Park KH (2011) Acute-onset bilateral myopia and ciliochoroidal effusion induced by hydrochlorothiazide. Korean J Ophthalmol 25: 214-7.

32. Richa S, Yazbek JC (2010) Ocular adverse effects of common psychotropic agents: a review. CNS Drugs 24: 501-26.

33. Gubbay SS (1998) The occurrence of drug-induced myopia as a transient side effect of topiramate. Epilepsia 39: 451.

34. Bhattachrayya KB, Basu S (2005) Acute myopia induced by topiramate: report of a case and review of the literature. Neurol India 53:108-9.

35. Desai CM, Ramchandani SJ, Bhopale SG, Ramchandani SS (2006) Acute myopia and angle closure caused by topiramate, a drug used for prophylaxis of migraine. Indian J Ophthalmol 54: 195-7.

36. Rodríguez-Blanco M, Piñeiro A, Bande M, López-Valladares MJ (2012) Angle-closure glaucoma secondary to topiramate use. Arch Soc Esp Oftalmol 87: 122-4.

37. Latini MF, Romano LM (2012) Topiramate-induced acute myopia with MRI contrast enhancement. Acta Neurol Belg 112: 81-4.

38. Caglar C, Yasar T, Ceyhan D (2012) Topiramate induced bilateral angle-closure glaucoma: low dosage in a short time. J Ocul Pharmacol Ther 28: 205-7. 
39. Muniesa Royo MJ, Traveset Maeso A, Jurjo Campo C (2012) Topiramate-induced bilateral acute angle closure glaucoma and myopia . Med Clin (Barc) 138: 368-9.

40. Dorronzoro E, Santos-Bueso E, Vico-Ruiz E, Sáenz-Frances F, Argaya J, et al. (2011) Myopia and retinal striae induced by topiramate. Arch Soc Esp Oftalmol 86: 24-6.

41. van Issum C, Mavrakanas N, Schutz JS, Shaarawy T (2011) Topiramate-induced acute bilateral angle closure and myopia: pathophysiology and treatment controversies. Eur J Ophthalmol 21: 404-9.

42. Kumar M, Kesarwani S, Rao A, Garnaik A (2012) Macular folds: an unusual association in topiramate toxicity. Clin Exp Optom 95: 449-52.

43. Vilar Ventura RM, Vilar Fabra C, Ramos Martí F (2009) Acute myopia secondary to treatment with topiramate. Neurologia 24: 350.

44. Gawley SD (2009) Topiramate induced acute transient myopia: a case report. Cases J 2: 7430

45. Cruciani F, Lorenzatti M, Nazzarro V, Abdolrahimzadeh S (2009) Bilateral acute angle closure glaucoma and myopia induced by topiramate. Clin Ter 160: 215-6.

46. Kerimoglu H, Tokgoz M, Ozturk B, Gonul S, Pekel H, (2009) Topiramate-induced acute-onset myopia and central corneal thickening: Pentacam Scheimpflug imaging findings. Can J Ophthalmol 44: 222-3.

47. Brandão MN, Fernandes IC, Barradas FF, Machado JF, Oliveira MT (2009) Acute myopia and angle closure glaucoma associated with topiramate use in a young patient: case report [Article in Portuguese]. Arq Bras Oftalmol 72: 103-5.

48. Boonyaleephan S (2008) Bilateral acute onset myopia and angle closure glaucoma after oral topiramate: a case report. J Med Assoc Thai 91: $1904-7$.

49. Mandal A, Chatterjee S, Bose S, Ganguly G (2008) Ocular adverse effects of Topiramate: Two case reports. Indian J Pharmacol 40: 278-80.

50. Guier CP (2007) Elevated intraocular pressure and myopic shift linked to topiramate use. Optom Vis Sci 84: 1070-3.

51. Saffra N, Smith SN, Seidman CJ (2012) Topiramate-induced refractive change and angle closure glaucoma and its ultrasound biomicroscopy findings. BMJ Case Rep

52. Bard LA (1964) Transient myopia associated with promethazine (Phenergan) therapy. Report of a case. Am J Ophthalmol 58: 682-6.

53. Yasuna E (1962) Acute myopia associated with prochlorperazine (Compazine) therapy. Am J Ophthalmol 54: 793-6.

54. Penha AM, Burkhardt E, Schaeffel F, Feldkaemper MP (2012) Effects of intravitreal insulin and insulin signaling cascade inhibitors on emmetropization in the chick. Mol Vis 18: 2608-22.

55. Lin SF, Lin PK, Chang FL, Tsai RK (2009) Transient hyperopia after intensive treatment of hyperglycemia in newly diagnosed diabetes. Ophthalmologica 223: 68-71.

56. Feldkaemper MP, Neacsu I, Schaeffel F (2009) Insulin acts as a powerful stimulator of axial myopia in chicks. Invest Ophthalmol Vis Sci 50: 13-23.

57. Zhu ZC, Zhang JS, Ji XY, Wang YF, Chen Y, et al. (2007) Insulin-like growth factor-1 induced activation and expression of signal transducers and activators of transcription-3 in scleral fibroblast of guinea pigs [Article in Chinese]. Zhonghua Yan Ke Za Zhi 43: 1125-9.

58. Ritchey ER, Zelinka CP, Tang J, Liu J, Fischer AJ (2012) The combination of IGF1 and FGF2 and the induction of excessive ocular growth and extreme myopia. Exp Eye Res 99 : 1-16.

59. Marcus MW, Müskens RP, Ramdas WD, Wolfs RC, de Jong PT, et al. (2012) Antithrombotic medication and incident open-angle glaucoma. Invest Ophthalmol Vis Sci 53: 3801-5.

60. Paur R, Wallner C, Hermann P, Stöllberger C, Finsterer J (2012) Neurological abnormalities in opiate addicts with and without substitution therapy. Am J Drug Alcohol Abuse 38: 239-45.

61. Edwards TS (1963) Transient myopia due to tetracycline. JAMA 186: 69-70.

62. Selvi Y, Atli A, Aydin A, Yener HI (2011) Aripiprazole-related acute transient myopia and diplopia: a case report. J Clin Psychopharmacol 31: 249-50.

63. Nair AG, Nair AG, George RJ, Biswas J, Gandhi RA (2012) Aripiprazole induced transient myopia: a case report and review of literature. Cutan Ocul Toxicol 31: 74-6.

64. Stratos AA, Peponis VG, Portaliou DM, Stroubini TE, Skouriotis S, et al. (2011) Secondary pseudomyopia induced by amisulpride. Optom Vis Sci 88: 1380-2. 65. Lee JW, Lee JE, Choi HY, Lee JS (2013) Oseltamivir (Tamiflu)-induced bilateral acute angle closure glaucoma and transient myopia. Indian J Ophthalmol 66. Vishwakarma P, Raman GV, Sathyan P (2009) Mefenamic acid-induced bilateral transient myopia, secondary angle closure glaucoma and choroidal detachment. Indian J Ophthalmol 57:398-400.

67. Kumar RS, Grigg J, Farinelli AC (2007) Ecstasy induced acute bilateral angle closure and transient myopia. Br J Ophthalmol 91: 693-5.

68. Lee W, Chang JH, Roh KH, Chung JK, Ohn YH (2007) Anorexiant-induced transient myopia after myopic laser in situ keratomileusis. J Cataract Refract Surg 33: $746-9$.

69. Milea D, Zech C, Dumontet C, Coiffier B, Trepsat C (1999) Transient acute myopia induced by antilymphocyte globulins. Ophthalmologica 213: 133-4.

70. Grinbaum A, Ashkenazi I, Avni I, Blumenthal M (1992) Transient myopia following metronidazole treatment for Trichomonas vaginalis. JAMA 267: 511-2

71. Sandford-Smith JH (1974) Transient myopia after aspirin. Br J Ophthalmol 58: 698-700.

72. Améline B, Ducasse A, Bailly JP, Melin JP, Wynckel A, et al. (1990) A case of acute myopia with angle-closure glaucoma. Bull Soc Ophtalmol Fr 90: 101-4.

73. Palestine AG (1984) Transient acute myopia resulting from isotretinoin (accutane) therapy. Ann Ophthalmol 16: 660-2.

74. Dangel ME, Weber PA, Leier CB (1983) Transient myopia following isosorbide dinitrate. Ann Ophthalmol 15: 1156-8.

75. Segal A, Aisemberg A, Ducasse A (1983) [Quinine, transient myopia and angle-closure glaucoma]. Bull Soc Ophtalmol Fr 83: 247-9.

76. Postel EA, Assalian A, Epstein DL (1996) Drug-induced transient myopia and angle-closure glaucoma associated with supraciliary choroidal effusion. Am J Ophthalmol 122: 110-2.

77. Ciuffreda KJ, Ordonez X (1995) Abnormal transient myopia in symptomatic individuals after sustained nearwork. Optom Vis Sci 72: 506-10.

78. Ong E, Ciuffreda KJ (1995) Nearwork-induced transient myopia: a critical review. Doc Ophthalmol 91: 57-85.

79. Güell JL, Morral M, Gris O, Elies D, Manero F (2012) Transient myopic shift after phakic intraocular lens implantation. J Cataract Refract Surg 38: 1283-7.

80. Herbort CP, Papadia M, Neri P (2011) Myopia and inflammation. J Ophthalmic Vis Res 6: 271-283. 
81. Grenet T, Streho M, Nicolon L, Puech M, Chaine G (2011) A case report of transient myopia following blunt trauma. J Fr Ophtalmol 34: 127.e1-4.

82. Küchle M, Naumann GO (2003) Transient myopia after trauma. Ophthalmology 110: 1285-6.

83. Ikeda N, Ikeda T, Nagata M, Mimura O (2002) Pathogenesis of transient high myopia after blunt eye trauma. Ophthalmology 109: $501-7$.

84. Doğanay S, Er H, Hepşen IF, Evereklioğlu C (2001) Bilateral myopia following blunt trauma to one eye. Eur J Ophthalmol 11: 83-5.

85. Guerriero S, Ciracì L, Cardia G, Vetrugno M (2010) Transient myopic shift as the presenting symptom of systemic lupus erythematosus: a UBM study. Ocul Immunol Inflamm 18: 383-4.

86. Hung KC, Hsueh PY, Wang NK, Su WW, Tan HY (2011) Transient myopic shifting in systemic lupus erythematosus. Lupus 20: 334-5.

87. Bohgaki T, Mukai M, Notoya A, Kondo M, Kohno M, et al. (2001) Transient myopia with severe chemosis as an initial manifestation of systemic lupus erythematosus. Mod Rheumatol 11: 165-7.

88. Shu U, Takeuchi F, Tanimoto K, Moroi Y, Uchida K, et al. (1992) Transient myopia with severe chemosis associated with exacerbation of disease activity in systemic lupus erythematosus. J Rheumatol 19: 297-301.

89. Aslam SA, Kashani S, Morley RK (2008) Systemic tuberculosis presenting with acute transient myopia: a case report. J Med Case Rep 2: 350.

90. Kusaka S, Okada AA, Hayashi A, Higaki S, Ohji M, et al. (2000) Ciliary body detachment associated with transient myopic shift after pars plana vitrectomy. Retina 20: 417-8.

91. Kusaka S, Mano T, Ohashi Y (1996) Transient myopia after pars plana vitrectomy. Ophthalmic Surg Lasers 27: 75-6.

92. Zamir E, Anteby I, Merin S (1996) Choroidal effusion causing transient myopia after panretinal photocoagulation. Arch Ophthalmol 114: 1284-5. 